\title{
Carbon nanoparticles downregulate expression of basic fibroblast growth factor in the heart during embryogenesis
}

This article was published in the following Dove Press journal:

International Journal of Nanomedicine

5 September 2013

Number of times this article has been viewed

\author{
Mateusz Wierzbicki' \\ Ewa Sawosz' \\ Marta Grodzik' \\ Anna Hotowy' \\ Marta Prasek' \\ Sławomir Jaworski' \\ Filip Sawosz ${ }^{2}$ \\ André Chwalibog 2 \\ 'Division of Nanobiotechnology, \\ Warsaw University of Life Sciences, \\ Warsaw, Poland; ${ }^{2}$ Department of \\ Veterinary Clinical and Animal \\ Sciences, University of Copenhagen, \\ Copenhagen, Denmark
}

Correspondence: André Chwalibog University of Copenhagen,

Department of Veterinary Clinical and Animal Sciences, Groennegaardsvej 3,

1870 Frederiksberg, Denmark

$\mathrm{Tel}+4535333044$

Fax +4535333020

Email ach@sund.ku.dk

\begin{abstract}
Carbon nanoparticles, with their high biocompatibility and low toxicity, have recently been considered for biomedical applications, including antiangiogenic therapy. Critical to normal development and tumor formation, angiogenesis is the process of forming capillary blood vessels from preexisting vessels. In the present study, we evaluated the effects of diamond and graphite nanoparticles on the development of chicken embryos, as well as vascularization of the chorioallantoic membrane and heart at the morphological and molecular level. Nanoparticles did not affect either body/heart weight or serum indices of the embryos' health. However, vascularization of the heart and the density of branched vessels were significantly reduced after treatment with diamond nanoparticles and, to a lesser extent, graphite nanoparticles. Application of nanoparticles significantly downregulated gene and protein expression of the proangiogenic basic fibroblast growth factor, indicating that both diamond and graphite nanoparticles inhibit angiogenesis.
\end{abstract}

Keywords: diamond, graphite, nanoparticles, vasculogenesis, bFGF, VEGF

\section{Introduction}

Increasing interest in the application of diamond nanoparticles (ND) also referred to as nanodiamonds in biomedicine continues due to their high biocompatibility and low toxicity. ${ }^{1,2}$ In vitro investigations have shown that the biocompatibility of ND is significantly higher than other forms of carbon nanoparticles. Moreover, ND do not generate reactive oxygen species and have been shown to be nontoxic in neuroblastoma cells. ${ }^{3}$ Furthermore, at concentrations ranging from $1-100 \mu \mathrm{g} / \mathrm{mL}$, ND do not affect protein expression or morphology of epithelial and fibroblast cell lines. ${ }^{4}$ Additionally, ND do not initiate an inflammatory response from macrophages. ${ }^{5}$ It has also been suggested that ND accumulate in lung tissue and interact with cell membrane proteins, but their existence inside the cells does not cause pulmonary toxicity. ${ }^{4}$ In vivo studies did not observe any negative effects in laboratory animals. ND administered to mice over 6 months has not been shown to have any detrimental effects on growth and development, fertility, and immunity, as well as biochemical and morphological parameters of blood. ${ }^{1,6}$ Another study determined that ND had no effect on the expression of cytokine genes involved in cellular inflammation. ${ }^{2}$

In HL-60 cells, a human promyelocytic leukemia cell line, it has been demonstrated that ND are biologically active upon administration. Specifically, they can influence expression of genes involved in cellular and genotoxic stress, and activate oxidative stress defense mechanisms. ${ }^{7,8}$ Furthermore, ND regulate phagocyte activity of neutrophils in the inflammatory site. ${ }^{9}$ In a previous study by our research group, ND down- 
regulated expression of basic fibroblast growth factor (bFGF) at the messenger ribonucleic acid (mRNA) level in tumor cell cultures of glioblastoma multiforme cultured in ovo, leading to a decrease in both tumor size and mass. ${ }^{10}$ Similar antiangiogenic activities (ie, decreasing angiogenesis induced by bFGF and vascular endothelial growth factor [VEGF]) were observed after application of graphite nanoparticles (GR), multiwalled carbon nanotubes, and fullerenes. ${ }^{11}$ The biological activities of GR have not been studied in detail; however, graphite particles of $1 \mu \mathrm{m}$ diameter have been shown to elicit an inflammatory reaction by murine macrophage cells ( 774 cell line) that was much more intensive than after fullerenes and single wall nanotubes treatment. Moreover, graphite particles led to severe cell damage and death. ${ }^{12}$ Inflammatory responses were also observed in rats after inhalation of graphite particles. ${ }^{13}$

Angiogenesis is the process of forming capillary blood vessels from preexisting vessels. ${ }^{14}$ It is required for embryonic development, ${ }^{15}$ wound healing, and tissue repair. ${ }^{16}$ bFGF has the ability to regulate the growth and function of vascular cells, such as endothelial and smooth muscle cells, by stimulating the growth and development of new blood vessels, but it is also a potent angiogenic molecule. ${ }^{17,18} \mathrm{VEGF}$ is an established regulator of angiogenesis, and is more efficient than bFGF for stimulation of endothelial cell differentiation. ${ }^{19}$ Therefore, the antiangiogenic properties of carbon nanoparticles may be a double-edged sword. In tumor cells, such antiangiogenic properties are beneficial for treatment of disease; in normal cells, however, growth and development of the vascular system may be inadvertently reduced, leading to inefficient supply of nutrients and oxygen to normal tissue, resulting in severe defects and embryolethality. ${ }^{20,21}$ Furthermore, disruption of angiogenesis has been proposed to be a sensitive method for developmental toxicity evaluation of environmental chemicals acting as putative vascular disruptor compounds. ${ }^{22,23}$
We hypothesized that both ND and GR may reduce blood vessel formation and affect development of the circulatory system by inhibiting proangiogenic factors. The objective of the present study was to evaluate the effects of ND and GR on growth and development of chicken embryos with particular emphasis on the vascular system and heart vascularization at the morphological and molecular level.

\section{Materials and methods Nanoparticles}

ND (explosion synthesized; specific surface area, $\sim 282 \mathrm{~m}^{2} / \mathrm{g}$; purity, $>95 \%$ ) and GR (explosion synthesized; specific surface area, 540-650 m²/g; purity, >93\%) were obtained from Sky Spring Nanomaterials Inc (Houston, TX, USA).

The nanoparticles were examined using a JEM-2000EX transmission electron microscope (TEM) at $200 \mathrm{kV}$ (JEOL, Tokyo, Japan). Typical TEM images of nanoparticles are presented in Figure 1. ND and GR ranged in size from 1-5 nm. Nanoparticles were dispersed by sonification in MilliQ water (EMD Millipore, Billerica, MA, USA) to obtain concentrations of 50,500 , or $5,000 \mu \mathrm{g} / \mathrm{mL}$. Zeta potential of $50 \mu \mathrm{g} / \mathrm{mL}$ colloids was measured by the laser dynamic scattering-electrophoretic method with Smoluchowski approximation using a Zetasizer Nano ZS, model ZEN3500 (Malvern Instruments, Malvern, UK). Each sample was measured after 120 seconds of stabilization at $25^{\circ} \mathrm{C}$. Observed zeta potential for ND and GR was $-39.3 \mathrm{mV}$ and $28.7 \mathrm{mV}$, respectively.

\section{Animal models}

Fertilized eggs $(n=120)$ from Ross Line 308 hens were obtained from a commercial hatchery, stored for 4 days at $12^{\circ} \mathrm{C}$, then incubated under standard conditions $\left(37^{\circ} \mathrm{C}, 60 \%\right.$ humidity, turned once per hour). Prior to incubation, the eggs were weighed and randomly divided into three groups, each with 40 eggs. Group I was the control group, treated with
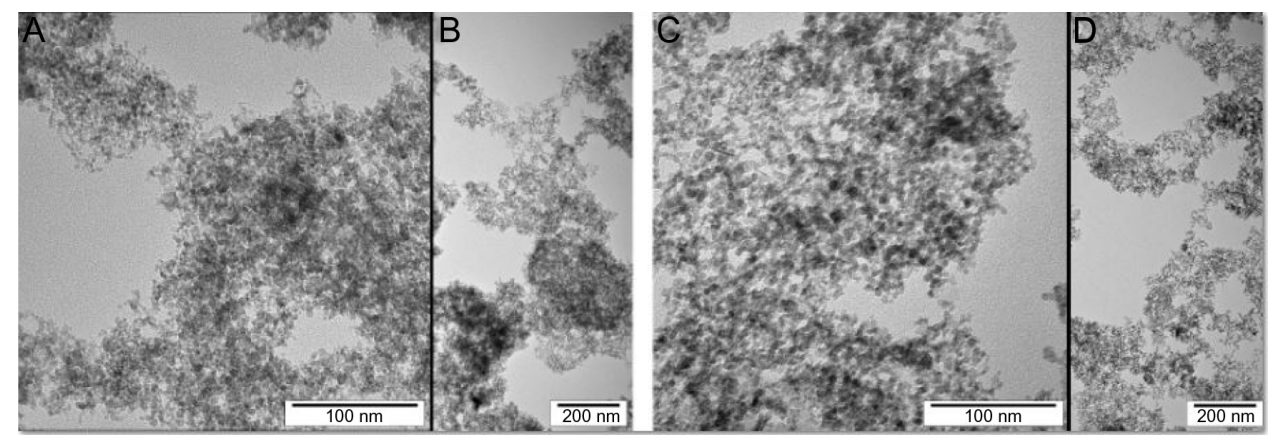

Figure I Transmission electron microscopy images of nanoparticles. Note: Images of ND (A and B) and GR (C and $\mathbf{D})$.

Abbreviations: ND, diamond nanoparticles; GR, graphite nanoparticles. 
phosphate buffered saline (PBS). Group II was treated with ND, while group III was treated with GR. Experimental solutions were administered in ovo, at the beginning of incubation, by injection of $0.3 \mathrm{~mL}$ PBS containing nanoparticle colloids $(50,500$, or $5,000 \mu \mathrm{g} / \mathrm{mL})$ into the air sack using a sterile $1 \mathrm{~mL}$ tuberculin syringe. Hydrocolloids of ND $(50,500$, or $5,000 \mu \mathrm{g} / \mathrm{mL}$ ) injected into eggs were a source of carbon nanoparticles in a dose of on average $0.3,3.2$ and $31.8 \mathrm{~g} / \mathrm{kg}$ body weight, respectively. Hydrocolloids of GR (50, 500 or $5,000 \mu \mathrm{g} / \mathrm{mL}$ ) were a source of carbon nanoparticles in a dose of average $0.3,3.3$ and $32.8 \mathrm{~g} / \mathrm{kg}$ body weight. After 19 days of incubation, embryos were sacrificed by decapitation and weighed. The hearts were dissected, fixed in liquid nitrogen, and stored at $-80^{\circ} \mathrm{C}$ until further analyses. Blood was taken during decapitation, and serum was collected after centrifugation at 3,000 rpm for 15 minutes.

\section{Angiogenesis assay}

For the evaluation of vascular systems growing outside the embryo, eggs were divided into three groups (30 eggs in each), and then injected with various experimental solutions (PBS, ND, and GR). After 11 days of incubation, embryos were very gently held out on the Petri dish, and the vascular system was examined using an Olympus SZX10 stereoscopic microscope with Imaging Software Cell (Olympus Corporation, Tokyo, Japan).

Angiogenesis was evaluated using the chicken embryo chorioallantoic membrane (CAM) vascularization method. Briefly, gelatin sponges (Pfizer, Inc, New York, NY, USA) and Whatman filter paper rings (10 $\mathrm{mm}$ diameter) were soaked in PBS, proangiogenic factor-bFGF (positive control), and hydrocolloids of ND or GR. Gelatin sponges or filter papers were implanted on top of the growing CAM on day 8 of incubation. ${ }^{24}$ After 3 days of incubation, a $1 \mathrm{~cm}^{2}$ window in the shell was created to remove $3 \mathrm{~mL}$ of albumin. The window was sealed with sterile aluminum foil, and eggs were incubated for an additional 5 days. On day 8 of incubation, windows were opened and sterile gelatin sponges or filter paper soaked in PBS containing nanoparticle solutions were placed over the developing CAM. Windows were again sealed, and embryos were incubated for an additional 3 days. On day 11 of incubation, morphology of blood vessels around the implant was examined using an Olympus SZX10 microscope with Imaging Software Cell. The methodology of quantifying blood vessel development on paper implant was the same as described before. ${ }^{25}$ Blood vessel length and number of branch points were calculated from seven chicken embryo CAM images from each group.
Photos were analyzed with CellSens Dimension Desktop version 1.3 (Olympus Corporation).

\section{Protein expression of bFGF}

A heart sample was placed in chilled RIPA (RadioImmunoprecipitation Assay) buffer ( $150 \mathrm{mM}$ sodium chloride, $0.5 \%$ sodium deoxycholate, $1 \%$ NP-40, $0.1 \%$ sodium dodecyl sulfate [SDS], $50 \mathrm{mM}$ tris(hydroxymethyl)aminomethane pH 7.4) with protease inhibitors (Sigma-Aldrich, St Louis, MO, USA) in an ice bath then homogenized using a Polytron PT-MR 2100 (Kinematica AG, Lucerne, Switzerland). The homogenate was centrifuged, and the supernatant was collected in chilled microtubes. Protein concentration was measured using a Total Protein Kit (Micro Lowry, Peterson's Modification, Sigma-Aldrich). bFGF protein level was measured using an enzyme-linked immunosorbent assay (ELISA) kit for gallinaceous bFGF (Uscn Life Science Inc., Houston, TX, USA) according to manufacturer's instructions. Absorbance at $450 \mathrm{~nm}$ was measured in an Infinite M200 microplate reader (Tecan Group AG, Männedorf, Germany).

\section{mRNA expression of bFGF and VEGF}

Ribonucleic acid (RNA) was purified using the SV Total RNA Isolation System (Promega Corporation, Fitchburg, WI, USA) and quantified using a NanoDrop spectrophotometer (Thermo Fisher Scientific, Waltham, MA, USA). It was transcribed into complementary deoxyribonucleic acid (cDNA) using both random hexamer priming and oligo (dT), and the products of these reactions were mixed. The polymerase chain reaction (PCR) primer oligonucleotides (Table 1) were designed from chicken mRNA sequences for $V E G F$ and $b F G F$, and the PCR conditions were optimized on chicken heart cDNA samples. The primers amplified the expected band on the cDNA samples from control chicken. Quantification of cDNA was subsequently performed by real-time PCR using SYBR Green I detection and the LightCycler System (F Hoffmann-La Roche Ltd, Basel, Switzerland). For each sample, 200 ng of a cDNA template was added to $12.5 \mu \mathrm{L}$ of QuantiTect SYBR Green Master IX (Qiagen, Hilden, Germany), $0.15 \mu \mathrm{L}$ of both forward and reverse primers (final concentration of $0.6 \mu \mathrm{M}$ each), and RNA-free water to a final volume of $20 \mu \mathrm{L}$. An initial denaturing step at $95^{\circ} \mathrm{C}$ for 15 minutes was followed by 40 cycles with a denaturing step at $94^{\circ} \mathrm{C}$ (15 seconds), an annealing step at $56^{\circ} \mathrm{C}$ (30 seconds), and an elongation step at $72^{\circ} \mathrm{C}$ (60 seconds). The cycling reports and melting curves were evaluated as part of the analysis. All reactions were 
Table I Oligonucleotide sequences used in real-time PCR

\begin{tabular}{lllll}
\hline $\begin{array}{l}\text { Target } \\
\text { gene }\end{array}$ & Forward primer & Reverse primer & $\begin{array}{l}\text { Product size } \\
\text { (base pairs) }\end{array}$ & $\begin{array}{l}\text { Annealing } \\
\text { temperature }\end{array}$ \\
\hline VEGF & TGA GGG CCT AGA ATG TGT CC & TCT TTT GAC CCT TCC CCT TT & 194 & $62^{\circ} \mathrm{C}$ \\
bFGF & GGC ACT GAA ATG TGC AAC AG & TCC AGG TCC AGT TTT TGG TC & 151 & $62^{\circ} \mathrm{C}$ \\
EEFIA2 & AGC AGA CTT TGT GAC CTT GCC & TGA CAT GAG ACA GAC GGT TGC & 85 & $62^{\circ} \mathrm{C}$ \\
ACTB & GTC CAC CTT CCA GCA GAT GT & ATA AAG CCA TGC CAA TCT CG & 169 & $60^{\circ} \mathrm{C}$ \\
\hline
\end{tabular}

Abbreviations: PCR, polymerase chain reaction; VEGF, vascular endothelial growth factor; bFGF, basic fibroblast growth factor; EEFIA2, elongation factor I alpha 2; ACTB, beta-actin.

performed in triplicate. For all analyses, quantification was made relative to expression of actin beta $(A C T B)$ and elongation factor 1 alpha 2 (EEF1A2) housekeeping genes.

\section{Biochemical analysis}

Alanine transaminase (ALT) and asparagine transaminase (AST) activity were measured in blood serum collected from embryos using dry chemistry methods that required use of a chemical analyzer (Vitros DT 60 II) and slide kits from Johnson and Johnson (New Brunswick, NJ, USA). Total antioxidant status (TAS) was measured in serum using a Randox Laboratories Ltd kit (London, UK).

\section{Statistical analysis}

Data analyses were conducted in $\mathrm{SAS}^{26}$ (SAS Institute Inc, Cary, NC, USA) using a general linear model procedure. Differences between groups were tested by least square means. Statistical significance was defined as $P<0.05$.

\section{Results}

\section{CAM angiogenesis}

Development of blood vessels after treatments with ND and GR was initially evaluated on chicken embryo CAM after
11 days of incubation. In all groups, blood vessel networks were properly organized with a characteristic branched pattern (Figure 2). However, density of vessels, especially small capillary vessels, growing on CAM was slightly reduced in treatment groups compared to the control embryos. To verify these observations, the experiment with implantation of gel sponge soaked with PBS, ND, GR, and proangiogenic factor (bFGF) was carried out. Evaluation of neovascularization of implants showed that the density of vessels branching, growing under the gel implant, was significantly reduced after ND treatment and, to a lesser extent, GR treatment compared to PBS and bFGF implants (Figure 2). A characteristic "spokedwheel" pattern was seen only around bFGF-soaked implants. Experiments with filter paper implants soaked with ND or GR showed similar results (Figure 2). Length of vessels treated with ND was decreased by $45 \%$ and for GR by $15 \%$ (mean length of blood vessels on $6.25 \mathrm{~mm}^{2}$ : control $9516 \mu \mathrm{m}$; ND $6123 \mu \mathrm{m}$; GR $8095 \mu \mathrm{m})$. The number of vessel branch points decreased after treatment with ND and GR by $35 \%$ and $14 \%$, respectively (mean number of branch points on $6.25 \mathrm{~mm}^{2}$ : control 11.0; ND 9.6; GR 7.2). Moreover, the implants were poorly furnished with CAM mesenchymal cells, and some of the discs soaked with ND did not adhere to CAM and were not



Figure 2 CAM vascularization.

Notes: Filter paper implants: (A) control group; (B) ND-treated group; and (C) GR-treated group. Gelatin sponges: (D) control group; (E) positive control with bFGF; (F) diamond nanoparticles-treated group; and (G) GR-treated group. Representative vessels of control CAM (A) and after the administration of (B) ND and (C) GR. Abbreviations: CAM, chorioallantoic membrane; ND, diamond nanoparticles; GR, graphite nanoparticles; bFGF, basic fibroblast growth factor. 
covered by cells. Furthermore, vessels infiltrating filter discs were absent or rarely seen. This observation was confirmed also on CAM vessels after injection of nanoparticles into the air sack (Figure 3). Nanoparticles that agglomerated were attached to the CAM blood vessels, suggesting that some of the nanoparticles reached the blood-circulating system.

\section{Body weight and health indices}

Chicken embryo development was evaluated on day 19 of incubation. $\mathrm{ND}$ and GR at $50,500 \mu \mathrm{g} / \mathrm{mL}$ (data not shown) or $5,000 \mu \mathrm{g} / \mathrm{mL}$ (Table 2) were not harmful to embryos, and there were no differences in body and heart weights between the groups. Macroscopic morphological abnormalities were not seen.

The activities of plasma serum ALT and AST were not affected by nanoparticles. Similarly, the TAS was not different between groups (Table 2).

\section{Heart examination}

Vascularization of the heart (Figure 4) in the ND and GR groups was less developed than in the control group. Injection of ND or GR at concentrations of 50 and $500 \mu \mathrm{g} / \mathrm{mL}$ did not influence $b F G F$ and $V E G F$ gene expression in the heart (Table 3). However, 5,000 $\mu \mathrm{g} / \mathrm{mL}$ ND or GR significantly decreased expression of $b F G F$, but not $V E G F$, at the mRNA level. The results measured with the reference gene $A C T B$ were validated with the reference gene EEF1A2 and were in agreement with the concentrations of the bFGF protein (Table 2).
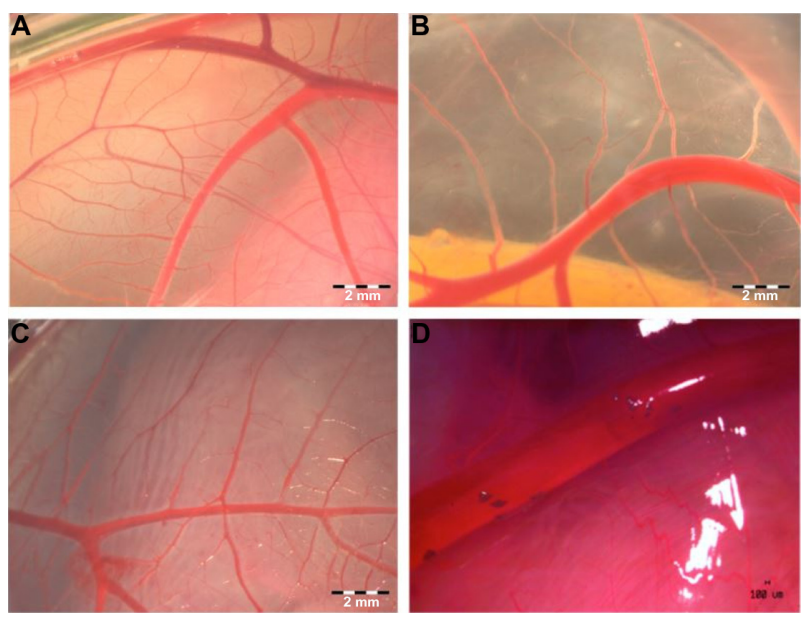

Figure 3 Visualization of CAM vascularization in II-day-old chicken embryo. Notes: Experimental solutions were administered in ovo by injection of $0.3 \mathrm{~mL}$ PBS containing hydrocolloids of ND or GR $(5,000 \mu \mathrm{g} / \mathrm{mL})$ into the air sack. (A) Control CAM and CAM after the administration of (B) ND or (C) GR. Agglomerates of ND located around vessels (D).

Abbreviations: CAM, chorioallantoic membrane; PBS, phosphate buffered saline; ND, diamond nanoparticles; GR, graphite nanoparticles.
Table 2 Body weight, heart weight, and biochemical parameters of chicken embryos

\begin{tabular}{|c|c|c|c|c|c|}
\hline & \multicolumn{3}{|l|}{ Group } & \multicolumn{2}{|c|}{ ANOVA } \\
\hline & Control & ND & GR & SEM & $P$-value \\
\hline Body weight $(g)^{a}$ & 48.3 & 47.2 & 45.8 & 0.708 & 0.4010 \\
\hline Heart weight $(g)^{a}$ & 0.26 & 0.26 & 0.27 & 0.011 & 0.5810 \\
\hline $\begin{array}{l}\text { Heart weight } / 100 \mathrm{~g} \\
\text { body weight }^{2}\end{array}$ & 0.53 & 0.55 & 0.59 & 0.016 & 0.4801 \\
\hline $\operatorname{ALT}(\mathrm{U} / \mathrm{L})^{\mathrm{b}}$ & 13.5 & 18.0 & 12.4 & 0.23 & 0.2208 \\
\hline AST (U/L) & 242 & 268 & 235 & 12.9 & 0.1349 \\
\hline $\begin{array}{l}\text { Total antioxidant } \\
\text { status }(\mathrm{mmol} / \mathrm{L})^{\mathrm{b}}\end{array}$ & 1.55 & 1.47 & 1.45 & 0.124 & 0.4500 \\
\hline bFGF protein $\mathrm{pg} / \mathrm{mL}^{\mathrm{c}}$ & $66.1 *$ & $53.9 * *$ & $57.6 * *$ & 3.07 & 0.0143 \\
\hline
\end{tabular}

Notes: Activity of ALT, AST, and total antioxidant status in blood serum. bFGF protein expression in the heart of embryos. Mean values for the control group and groups administered with $5,000 \mu \mathrm{g} / \mathrm{mL}$ hydrocolloids of ND and GR. *, ** values within rows with different superscripts are significantly different, $P<0.05$. ${ }^{a} \mathrm{n}=40$; ${ }^{b} n=8 ;{ }^{c} n=5$.

Abbreviations: ND, diamond nanoparticles; GR, graphite nanoparticles; ANOVA, analysis of variance; SEM, standard error of mean; ALT, alanine transaminase; AST, asparagine transaminase; bFGF, basic fibroblast growth factor.

\section{Discussion}

A chicken embryo possesses several experimental advantages as a biological model. Avian embryos develop outside mother organisms, and therefore exclude direct effects of the mother. Embryo development in the egg is sterile and immunologically inert. ${ }^{27}$ Furthermore, development of part of the vascular system outside of the embryo's body allows for easier evaluation. Moreover, embryo growth is very fast. Cell proliferation and differentiation are extremely fast, and molecular reactions are prompt and potent; consequently, the responses to toxic factors are fast and very sensitive. Hence, this model is often used to investigate angiogenesis ${ }^{25,27,28}$ and evaluate toxicity of drugs and other supplements in humans. ${ }^{29,30}$

Evaluation of chicken embryo morphology indicated that neither ND nor GR were harmful to embryos. The activities of ALT and AST markers of hepatic and muscle (including heart muscle) cell membrane integrity were also not changed. An increased activity of these enzymes in blood may be an indication that cytoplasm is leaking from cells, which may be a symptom of toxicity due to ND or GR. For instance, elevated levels of ALT were observed after treating zebrafish with copper nanoparticles at $1.5 \mu \mathrm{g} / \mathrm{mL},{ }^{31}$ mice with titanium dioxide and zinc nanoparticles $(5 \mathrm{~g} / \mathrm{kg}$ body weight $),{ }^{32}$ gold nanoshells $(57 \mu \mathrm{g} / \mathrm{mL}){ }^{33}$ In the present investigation, the highest concentration $(5,000 \mu \mathrm{g} / \mathrm{mL})$ of ND and GR injected into eggs were a source of carbon nanoparticles in a dose of on average $31.8 \mathrm{~g} / \mathrm{kg}$ body weight for ND and $32.8 \mathrm{~g} / \mathrm{kg}$ for GR, which were relatively high doses. Oxidative stress is an important pathway of toxicity of nanomaterials and 



Figure 4 Images of chicken embryo heart.

Notes: Experimental solutions were administered in ovo by injection of $0.3 \mathrm{~mL}$ PBS containing 5,000 $\mu \mathrm{g} / \mathrm{mL}$ hydrocolloids of nanoparticles into the air sack. (A) Control heart and after the administration of (B) ND or (C) GR.

Abbreviations: CAM, chorioallantoic membrane; PBS, phosphate buffered saline; ND, diamond nanoparticles; GR, graphite nanoparticles.

elevation of TAS would indicate that tested nanoparticles trigger a defense mechanism against free radicals. In the present investigation, the antioxidant status measured in serum did not differ after treatments with ND or GR, suggesting that oxygen availability in the environment of the vascular endothelial cells was adequate and that hypoxia did not occur after administration of the carbon nanoparticles. Observed results confirm the suspected high biocompatibility of carbon nanoparticles, especially ND. ${ }^{1}$

A previous study by Marcon et $\mathrm{al}^{34}$ showed that 2-200 $\mu \mathrm{g} / \mathrm{mL} \mathrm{ND}$ (with $-\mathrm{OH}$ groups on the surface) injected into Xenopus embryos had no significant impact on embryo survival. However, the frequency of abnormally developed embryos increased, indicating mutagenic effects of ND. Contrary to Xenopus embryos, growth and development of chicken embryos in the present work were not affected by ND or GR (Table 2). Similarly, a different carbon nanomaterial (single wall nanotubes) did not show toxic side effects when used as a carrier of antiangiogenic drug thalidomide in the zebrafish embryos. ${ }^{35}$ Since ND was previously shown to decrease angiogenesis in glioblastoma multiforme cell cultures in ovo, ${ }^{10}$ we focused our investigation on the growth and development of the vascular

Table 3 Gene expression of bFGF and VEGF measured in heart tissue

\begin{tabular}{lllllll}
\hline & \multicolumn{3}{l}{ Group } & & & \multicolumn{2}{l}{ ANOVA } \\
\cline { 2 - 3 } \cline { 6 - 7 } & Control & ND & GR & & SEM & P-value \\
\hline bFGF mRNA* & $1.29^{\mathrm{a}}$ & $0.67^{\mathrm{b}}$ & $0.83^{\mathrm{a}, \mathrm{b}}$ & & 0.075 & 0.0114 \\
bFGF mRNA** & $1.38^{\mathrm{a}}$ & $0.7 \mathrm{I}^{\mathrm{b}}$ & $\left.0.9\right|^{\mathrm{a}, \mathrm{b}}$ & & 0.079 & 0.0104 \\
VEGF mRNA* & 1.00 & 0.83 & 0.89 & & 0.018 & 0.2026 \\
VEGF mRNA** & 1.06 & 0.99 & 0.99 & & 0.009 & 0.7366 \\
\hline
\end{tabular}

Notes: Mean values for the control group and groups administered 5,000 $\mu \mathrm{g} / \mathrm{mL}$ hydrocolloids of ND and GR nanoparticles. a, b values within rows with different superscripts are significantly different, $P<0.05, \mathrm{n}=5$. *Relative expression normalized against ACTB; **relative expression normalized against EEFIA2.

Abbreviations: $b F G F$, basic fibroblast growth factor; VEGF, vascular endothelial growth factor; ND, diamond nanoparticles; GR, graphite nanoparticles; ANOVA, analysis of variance; SEM, standard error of mean; ALT, alanine transaminase; AST, asparagine transaminase; mRNA, messenger ribonucleic acid. system in embryos. Vascular development has been used for embryonic development toxicity evaluation for drugs and chemicals using high-throughput screening. ${ }^{22,23}$ In the present experiment, density of vessels and branching were reduced in treatment groups compared to control embryos. Implants soaked with ND were poorly furnished with CAM mesenchymal cells, which suggests that ND inhibited growth of epithelial, endothelial, and fibroblast cells, as well as their precursors, consequently leading to inhibition of blood vessel growth. ND inhibited vasculogenesis and/or angiogenesis, whereas GR had a tendency to reduce vessel growth.

Nanoparticles that agglomerated after injection into the chicken embryo air sac were attached to the CAM blood vessels. This suggests that part of the nanoparticles reached the blood-circulating system and were transported within the organism. In vivo experiments have previously shown that ND intravenously injected into mice were retained in the liver, spleen, and lungs ${ }^{36}$ and that they accumulated in human lung cells. ${ }^{4}$ In the current study, the heart was the focus of investigation since it appears very early in chicken embryogenesis and is in permanent contact with blood. Examination of the heart (Figure 4) showed that vascularization in the ND and GR groups was less developed than in the control group. In light of this observation, we presumed that ND were able to downregulate genes responsible for migration of chorioallantoic cells, as well as differentiation and maturation, allowing mesenchymal cells to invade and initiate angiogenesis. Chorionic and other epithelial cells highly express bFGF protein, especially during the early stages of embryogenesis, ${ }^{37}$ and also stimulate endothelial cells to form new vessels. Additionally, endogenous chicken bFGF, expressed by endothelial cells, may play a significant role in CAM vascularization by potentially stimulating proliferation of endothelial cells to promote migration, redistribution, and invasiveness. ${ }^{38}$ This may indicate that ND and, to a lesser degree GR, downregulate $b F G F$ gene expression and in this way impair the environment for vessel development. 
VEGF is another key signaling factor that promotes angiogenesis and vasculogenesis. ND or GR at concentrations of $5,000 \mu \mathrm{g} / \mathrm{mL}$ decreased expression of bFGF at both the mRNA and protein level in the heart. This observation is consistent with the results from experiments with mice, which showed that the other form of carbon (endohedral fullerenes with encapsulated gadolinium) downregulates the expression of genes encoding the fibroblast growth factor family ( $F G F 1, F G F 3$, and $F G F 6) .{ }^{39}$ Furthermore, a decrease in $b F G F$ expression after treatment with carbon nanotubes, fullerenes, or graphite has been reported in previous studies. ${ }^{11}$ Observed results are also consistent with our previous study that showed that ND and GR cause a reduction in the concentration of bFGF in glioblastoma cultures in ovo. ${ }^{10}$ The FGF protein is a potent angiogenic factor. It also has a pleiotropic effect on cellular development and differentiation, including neuronal differentiation, smooth muscle cell proliferation, myogenesis, stimulation of hematopoiesis, stem cell survival, and antiapoptotic effects. ${ }^{17}$ Experiments carried out in vivo have shown the key role of bFGF in embryogenesis, especially in mesoderm induction..$^{40}$ The heart is the first embryonic organ to develop, arising from the splanchnic mesoderm. The endocardium and myocardium are created from delaminated epithelia. Additionally, de novo construction of blood vessels begins from splanchnic mesoderm cells, which after transformation become hemangioblasts - the precursors of blood vessels..$^{41}$ bFGF promotes proliferation and maintenance of hematopoietic progenitors and stem cells. ${ }^{42}$ Thus, from the very early stages of embryogenesis, bFGF controls processes of blood system initiation, growth, and development.

ND and GR did not influence $V E G F$ mRNA expression. VEGF is a multifunctional heparin-binding glycoprotein that primarily promotes the growth of vascular endothelial cells derived from arteries, veins, and the lymphatic system. This key prosurvival factor for endothelial cells acts via antiapoptotic pathways and is controlled by the autocrine or paracrine release of several major growth factors, depending on the oxygen status of the microenvironment and local hypoxia. ${ }^{43,44}$ However, embryo heart muscle may not be suitable tissue for VEGF measurements, and expression of this factor should be examined in vessels. ${ }^{45}$

Although ND and GR had no significant adverse effects on body weight and biochemical health indices of chicken embryos, results from the current study suggest that downregulation of bFGF by ND and GR may be a consequence of changes in mesoderm proliferation and inhibition of angioblast induction. Downregulation of bFGF can be beneficial in angiogenesis-dependent diseases and antitumor therapies, especially in case of anti-VEGF therapy resistance, characteristic for many tumor types. ${ }^{46}$ However, the disruption of angiogenesis by antiangiogenic tumor drugs may induce cardiac dysfunction ${ }^{47}$ and other severe side effects. ${ }^{48}$ Consequently, the antiangiogenic effects observed in the present CAM implantation experiments, as well as reduction of heart muscle vascularization, shall be considered prior to any therapeutic application of these nanoparticles; however, this has to be based on a follow-up, and more detailed research of other animal models.

\section{Conclusion}

Nanoparticles did not affect body weight and serum health indices of embryos. However, vascularization of the heart and the density of branched vessels were significantly reduced. Furthermore, high doses of ND and GR led to significant downregulation of bFGF expression in the heart, indicating that both ND and GR inhibit angiogenesis.

\section{Acknowledgments}

This work was supported by the Polish National Research Council grants: NCN 2011/03/N/NZ9/04290, NCN NN311540840, NCN 2011/03/B/NZ9/03387; and Danish Agency for Science Technology and Innovation grant: 210608-0025. The manuscript is a part of the doctoral thesis of Mateusz Wierzbicki.

\section{Disclosure}

The authors report no conflicts of interest in this work.

\section{References}

1. Schrand AM, Ciftan SA, Shenderova OA. Nanodiamond particles: properties and perspectives for bioapplications. Crit Rev Solid State Mat Sci. 2009;34(1-2):18-74.

2. Huang H, Pierstorff E, Liu K, Ōsawa E, Ho D. Nanodiamond-mediated delivery of therapeutics via particle and thin film architectures. In: Ho D, editor. Nanodiamonds: Applications in Biology and Nanoscale Medicine. New York: Springer: Science+Business Media; 2010:151-174.

3. Schrand AM, Dai L, Schlager JJ, Hussain SM, Ōsawa E. Differential biocompatibility of carbon nanotubes and nanodiamonds. Diamond Relat Mater. 2007;16(12):2118-2123.

4. Liu KK, Chen MF, Chen PY, et al. Alpha-bungarotoxin binding to target cell in a developing visual system by carboxylated nanodiamond. Nanotechnology. 2008;19(20):205102.

5. Thomas V, Halloran BA, Ambalavanan N, Catledge SA, Vohra YK. In vitro studies on the effect of particle size on macrophage responses to nanodiamond wear debris. Acta Biomater. 2012;8(5):1939-1947.

6. Puzyr AP, Baron AV, Purtov KV, et al. Nanodiamonds with novel properties: a biological study. Diamond Relat Mater. 2007;16(12): 2124-2128.

7. Bakowicz-Mitura K, Bartosz G, Mitura S. Influence of diamond powder particles on human gene expression. Surf Coat Techn. 2007;201(13): 6131-6135. 
8. Niemiec T, Szmidt M, Sawosz E, Grodzik M, Mitura K. The effect of diamond nanoparticles on redox and immune parameters in rats. J Nanosci Nanotechnol. 2011;11(10):9072-9077.

9. Karpukhin AV, Avkhacheva NV, Yakovlev RY, et al. Effect of detonation nanodiamonds on phagocyte activity. Cell Biol Int. 2011;35(7):727-733.

10. Grodzik M, Sawosz E, Wierzbicki M, et al. Nanoparticles of carbon allotropes inhibit glioblastoma multiforme angiogenesis in ovo. Int $J$ Nanomedicine. 2011;6:3041-3048.

11. Murugesan S, Mousa SA, O’connor LJ, Lincoln DW, Linhardt RJ. Carbon inhibits vascular endothelial growth factor- and fibroblast growth factor-promoted angiogenesis. FEBS Lett. 2007;581(6):1157-1160.

12. Fioritoa S, Serafinob A, Andreolab F, Bernierc P. Effects of fullerenes and single-wall carbon nanotubes on murine and human macrophages. Carbon. 2006;44(6):1100-1105.

13. Eriksson $C$, Nygren $H$. The initial reactions of graphite and gold with blood. J Biomed Mater Res. 1997;37(1):130-136.

14. Cross MJ, Claesson-Welsh L. FGF and VEGF function in angiogenesis: signalling pathways, biological responses and therapeutic inhibition. Trends Pharmacol Sci. 2001;22(4):201-207.

15. Tomanek RJ, Lotun K, Clark EB, Suvarna PR, Hu N. VEGF and bFGF stimulate myocardial vascularization in embryonic chick. Am J Physiol. 1998;274(5 Pt 2):H1620-H1626.

16. Tonnesen MG, Feng X, Clark RA. Angiogenesis in wound healing. J Investig Dermatol Symp Proc. 2000;5(1):40-46.

17. Bikfalvi A, Klein S, Pintucci G, Rifkin D. Biological roles of fibroblast growth factor-2. Endocrine Rev. 1997;18(1):26-45.

18. Nugent MA, Iozzo RV. Fibroblast growth factor-2. Int J Biochem Cell Biol. 2000;32(2):115-120.

19. Shinkaruk S, Bayle M, Laïn G, Déléris G. Vascular endothelial cell growth factor (VEGF), an emerging target for cancer chemotherapy. Curr Med Chem Anticancer Agents. 2003;3(2):95-117.

20. Coultas L, Chawengsaksophak K, Rossant J. Endothelial cells and VEGF in vascular development. Nature 2005;438(7070):937-945.

21. Brouillard P, Vikkula M. Genetic causes of vascular malformations. Hum Mol Genet. 2007;16 Spec No 2:R140-R149.

22. Knudsen TB, Kleinstreuer NC. Disruption of embryonic vascular development in predictive toxicology. Birth Defects Res C Embryo Today. 2011;93(4):312-323.

23. Kleinstreuer NC, Judson RS, Reif DM, et al. Environmental impact on vascular development predicted by high-throughput screening. Environ Health Perspect. 2011;119(11):1596-1603.

24. Ribatti D, Vacca A, Roncali L, Dammacco F. The chick embryo chorioallantoic membrane as a model for in vivo research on angiogenesis. Int J Dev Biol. 1996;40(6):1189-1197.

25. Wierzbicki M, Sawosz E, Grodzik M, Prasek M, Jaworski S, Chwalibog A. Comparison of anti-angiogenic properties of pristine carbon nanoparticles. Nanoscale Res Lett. 2013;8(1):195.

26. SAS Institute Inc. Base SAS 9.2 Procedures Guide. Cary, NC: SAS Institute Inc: 2009.

27. Ribatti D. Chorioallantoic membrane in the study of angiogenesis, antiangiogenesis, and the vascularization of grafted tissues. In: Ribatti D. The Chick Embryo Chorioallantoic Membrane in the Study of Angiogenesis and Metastasis. New York: Springer: Science+Business Media; 2010L:17-40.

28. Brooks PC, Montgomery AM, Cheresh DA. Use of the 10-day-old chick embryo model for studying angiogenesis. Methods Mol Biol. 1999;129:257-269.
29. Gvozdjan DM, Bowden ET, Wellstein A. A novel chicken embryo model for the investigation of drugs with antimetastatic properties. Clin Pharmacol Ther. 2004;75(2):P60.

30. Rashidi H, Sottile V. The chick embryo: hatching a model for contemporary biomedical research. Bioessays. 2009;31(4):459-465.

31. Griffitt RJ, Weil R, Hyndman KA, et al. Exposure to copper nanoparticles causes gill injury and acute lethality in zebrafish (Danio rerio). Environ Sci Technol. 2007;41(23):8178-8186.

32. Wang B, Feng WY, Wang TC, et al. Acute toxicity of nano- and microscale zinc powder in healthy adult mice. Toxicol Lett. 2006;161(2): $115-123$.

33. Terentyuk GS, Maslyakova GN, Suleymanova LV, et al. Circulation and distribution of gold nanoparticles and induced alterations of tissue morphology at intravenous particle delivery. J Biophotonics. 2009;2(5): 292-302.

34. Marcon L, Riquet F, Vicogne D, Szunerits S, Bodartb JF, Boukherroub R. Cellular and in vivo toxicity of functionalized nanodiamond in Xenopus embryos. J Mater Chem. 2010;20:8064-8069.

35. Cheng J, Gu YJ, Wang Y, Cheng SH, Wong WT. Nanotherapeutics in angiogenesis: synthesis and in vivo assessment of drug efficacy and biocompatibility in zebrafish embryos. Int J Nanomedicine. 2011;6: 2007-2021.

36. Yuan Y, Wang X, Jia G, et al. Pulmonary toxicity and translocation of nanodiamonds in mice. Diamond Relat Mater. 2010;19(4):291-299.

37. Abraham JA, Mergia A, Whang JL, et al. Nucleotide sequence of a bovine clone encoding the angiogenic protein basic fibroblast growth factor. Science. 1986;233(4763):545-548.

38. Ribatti D, Presta M. The role of fibroblast growth factor- 2 in the vascularization of the chick embryo chorioallantoic membrane. J Cell Mol Med. 2002;6(3):439-446.

39. Meng H, Xing G, Sun B, et al. Potent angiogenesis inhibition by the particulate form of fullerene derivatives. ACS Nano. 2010;4(5): 2773-2783.

40. Yamaguchi TP, Harpal K, Henkemeyer M, Rossant J. fgfr-1 is required for embryonic growth and mesodermal patterning during mouse gastrulation. Genes Dev. 1994;8(24):3032-3044.

41. Shalaby F, Ho J, Stanford WL, et al. A requirement for Flk1 in primitive and definitive hematopoiesis and vasculogenesis. Cell. 1997;89(6):981-990.

42. Moroni E, Dell'Era P, Rusnati M, Presta M. Fibroblast growth factors and their receptors in hematopoiesis and hematological tumors. J Hematother Stem Cell Res. 2002;11(1):19-32.

43. Ferrara N, Gerber HP, LeCouter J. The biology of VEGF and its receptors. Nat Med. 2003;9(6):669-676.

44. Ladoux A, Frelin C. Hypoxia is a strong inducer of vascular endothelial growth factor mRNA expression in the heart. Biochem Biophys Res Commun. 1993;195(2):1005-1010.

45. Dumont DJ, Fong GH, Puri MC, Gradwohl G, Alitalo K, Breitman ML. Vascularization of the mouse embryo: a study of flk-1, tek, tie, and vascular endothelial growth factor expression during development. Dev Dyn. 1995;203(1):80-92.

46. Bergers G, Hanahan D. Modes of resistance to anti-angiogenic therapy. Nat Rev Cancer. 2008;8(8):592-603.

47. Tocchetti CG, Gallucci G, Coppola C, et al. The emerging issue of cardiac dysfunction induced by antineoplastic angiogenesis inhibitors. Eur J Heart Fail. 2013;15(5):482-489.

48. Folkman J. Angiogenesis: an organizing principle for drug discovery? Nat Rev Drug Discov. 2007;6(4):273-286. 
International Journal of Nanomedicine

Dovepress

\section{Publish your work in this journal}

The International Journal of Nanomedicine is an international, peerreviewed journal focusing on the application of nanotechnology in diagnostics, therapeutics, and drug delivery systems throughou the biomedical field. This journal is indexed on PubMed Central, MedLine, CAS, SciSearch ${ }^{\circledR}$, Current Contents ${ }^{\circledR} /$ Clinical Medicine,
Journal Citation Reports/Science Edition, EMBase, Scopus and the Elsevier Bibliographic databases. The manuscript management system is completely online and includes a very quick and fair peer-review system, which is all easy to use. Visit http://www.dovepress.com/ testimonials.php to read real quotes from published authors.

Submit your manuscript here: http://www.dovepress.com/international-journal-of-nanomedicine-journal 